\title{
Does cavity reuse affect timing of reproduction and fledgling success in the Black Woodpecker?
}

\author{
Ziemowit Kosiński $^{1}$ D $\cdot$ Łukasz Walczak $^{1}$
}

Received: 6 March 2018 / Revised: 2 July 2018 / Accepted: 10 July 2018 / Published online: 23 July 2018

(c) The Author(s) 2018

\begin{abstract}
Nesting in old cavities may be adaptive for birds as it may offer an advantage of earlier laying and higher fitness through more recruiting offspring. Black Woodpeckers frequently use old cavities, which gives the opportunity to test how this behavior affects the timing and the success of reproduction. In this paper, we have tested a prediction that excavating a new cavity causes a delay in breeding, and that it is linked to lower productivity. We found that in the Wielkopolski National Park (western Poland) Black Woodpeckers nested exclusively in European beeches, mainly in living trees, and most frequently in their old cavities. The median relative egg-laying date in old cavities was 5.5 days earlier than in new cavities. We did not find a difference in clutch size between old and new cavities due to its low variation in the population. The proportion of offspring surviving to the end of the nestling period was 0.812 in old cavities and 0.632 in new cavities, although this did not differ significantly. However, survivorship dropped rapidly in the hatching period, especially in new cavities. In Black Woodpecker, the number of fledglings that succeeded was best explained by a model including the age of the cavity and the relative laying date. The estimated parameters of the best ranked model revealed that the number of fledglings is affected by the age of the cavity as it was higher for old cavities than for new cavities. This study shows that nest reuse is adaptive for primary excavators as it offers time and energy savings needed for cavity excavation, and increases productivity, compared to those pairs of birds that are forced to excavate a new cavity. These data are consistent with the hypothesis that cavity excavation is energetically expensive and support the prediction of tradeoffs between nest building and different components of reproduction. Responsible forest management should consider the need to protect living beeches with old cavities, which are frequently used by Black Woodpeckers.
\end{abstract}

Keywords Dryocopus martius $\cdot$ Cavity age $\cdot$ Nest reuse $\cdot$ Reproductive success $\cdot$ Costs of reproduction

\section{Zusammenfassung}

Beeinflusst beim Schwarzspecht das Wiederverwenden von alten Nisthöhlen den zeitlichen Ablauf der Fortpflanzung und den Bruterfolg?

In alten Nisthöhlen erneut zu brüten könnte Vögeln den Vorteil bieten, früher Eier legen zu können und so durch mehr Nachkommen eine größere Fitness zu realisieren. Da Schwarzspechte häufig alte Nisthöhlen wiederverwenden, bietet sich so eine Gelegenheit zu testen, ob diese Verhaltensweise den Brutzeitpunkt und den Bruterfolg beeinflusst. In unserer Untersuchung haben wir die Annahme geprüft, dass das Anfertigen einer neuen Nisthöhle das Brüten verzögert und dies eine niedrigere Reproduktionsrate zur Folge hat. Wir stellten fest, dass die Schwarzspechte im Wielkopolski Nationalpark (Westpolen) ausschließlich in der Europäischen Birke nisten, überwiegend in nicht abgestorbenen Bäumen und fast immer in ihren alten Nisthöhlen. Der Median für das Datum der Eiablage in den alten Nisthöhlen lag 5,5 Tage vor dem in neuen Nisthöhlen. Wegen der geringen Schwankungsbreite in der Population konnten wir für die Gelegegrößen keinen Unterschied zwischen alten und neuen Nisthöhlen feststellen. Der Anteil der bis zum Ende des Nestbaus überlebenden Individuen betrug 0,812 in alten und 0,632 in neuen Nisthöhlen; der Unterschied war nicht signifikant. Während der Brutzeit fiel die Überlebensrate jedoch drastisch, vor allem in neuen Nisthöhlen. Für Schwarzspechte kann die Anzahl der überlebenden

Communicated by F. Bairlein.

Extended author information available on the last page of the article 
Jungvögel am besten mit einem Modell erklärt werden, das das Alter der Nisthöhle und das relative Eiablage-Datum berücksichtigt. Die Parameter für das best-passende Modell zeigen, dass die Anzahl der Jungvögel vom Alter der Höhle abhängig ist mit mehr Jungen in alten im Vergleich zu neuen Höhlen. Unsere Untersuchung zeigt, dass die Wiederbenutzung von Nisthöhlen einen adaptiven Vorteil bietet, da sie gegenüber dem Bauen einer neuen Nisthöhle eine Zeit- und EnergieErsparnis bietet und im Vergleich zu Brutpaaren, die gezwungen sind, eine neue Nisthöhle zu bauen, eine größere Produktivität ermöglicht. Diese Ergebnisse stehen in Einklang mit der Hypothese, dass das Aushöhlen einer Nisthöhle hohe Energiekosten mit sich bringt, und sie unterstützen die Annahme eines Abwägens zwischen Nestbau und anderen Komponenten der Fortpflanzung. Eine verantwortungsvolle Waldbewirtschaftung sollte die Notwendigkeit berücksichtigen, Birken mit alten Nisthöhlen zu schützen, weil diese häufig von Schwarzspechten genutzt werden.

\section{Introduction}

During spring, individuals that reproduce earlier produce more surviving offspring than those that reproduce later (Perrins 1970). However, the timing of breeding within the season may be constrained by the costs of nest construction (Moreno et al. 2008). Nest building is an energetically expensive and time-consuming activity in most birds, which is why some bird species behave in ways that minimize nest building costs, e.g., breeding in old nests (Wiebe et al. 2007; Mainwaring and Hartley 2013; Pakkala et al. 2017).

The investment in nest building can be particularly high for primary excavators, e.g., the Black Woodpecker, Dryocopus martius, which selects living trees as nest substrate for cavity excavation (Meyer and Meyer 2001; Zahner et al. 2012). The time to complete the excavation process for this species can range from 2 weeks in softwood trees, e.g., poplars (Populus sp.) and willows (Salix sp.), to 5-6 years in hardwood trees, e.g., European beech Fagus sylvatica (Glutz von Blotzheim and Bauer 1980; Meyer and Meyer 2001). The high energetic costs of nest excavation may be the reason why Black Woodpeckers reuse old cavities multiple times (Lang and Rost 1990a; Nilsson et al. 1991; Christensen 2006). Previous studies suggest that this behavior may be adaptive for birds as it offers an advantage of earlier laying and higher fitness through more recruiting offspring. Life history theory predicts that if internal resources are limited and insufficient to pay all costs then the allocation to reproduction is shaped by physiological tradeoffs-an increment of internal resources allocated to one trait necessitates a decrement of resources allocated to another trait (Stearns 1992; Reid et al. 2000). Since excavating a new cavity requires time and energy, it must be offset by decreased investment in subsequent competing reproductive stages. Wiebe et al. (2007) found, in facultative excavators, a general pattern of later laying date and lower clutches in freshly excavated cavities compared to reused cavities. However, this latter study omitted other traits of reproduction, e.g., number of fledglings - an important determinant of the number of recruits (Newton 1989). Other studies suggest that the energetic costs of nest building may be carried over to the nestling phase or the second breeding attempt (Hauber 2002; Moreno et al. 2008; Mainwaring and Hartley 2016). Wiebe et al. (2007) emphasized that there are surprisingly few studies that have reported on reproductive parameters for new versus old cavities.

In terms of reproduction, the Black Woodpecker is most likely the best-studied woodpecker in Europe (Pasinelli 2006; Paclik et al. 2009; van Manen 2012). However, data describing the effect of cavity age on breeding success are quite scarce and inconclusive (Lang and Rost 1990a; Nilsson et al. 1991; Lange 1996; Rolstad et al. 2000). The Black Woodpecker is the largest woodpecker of the Palearctic region (Winkler and Christie 2002). As the major creator of large cavities, this species provides a critical resource for several large- and medium-size secondary cavity users (Lang and Rost 1990a; Johnsson et al. 1993; Lange 1993; Christensen 2004; Kosiński et al. 2010, 2011). The Black Woodpecker is listed in the Annex I of the European Union Birds Directive, and is the subject of special conservation measures concerning their habitat to ensure their survival and reproduction in their area of distribution. Thus, identifying different aspects of its breeding behavior is an important step in developing promising conservation strategies.

In this article, we examine the following: (1) is the timing of breeding delayed by the cost of cavity excavation, and (2) is the success of breeding higher in old than in new cavities? According to the cost of excavation model (Wiebe et al. 2007), we predicted that breeding should be earlier, and that breeding success could be higher in pairs nesting in old cavities relative to those that are forced into excavating a new cavity.

\section{Study area}

The study was conducted in the Wielkopolski National Park (WNP; 7584 ha in size apart from the buffer zone), western Poland $\left(52^{\circ} 16^{\prime} \mathrm{N}, 16^{\circ} 47^{\prime} \mathrm{E}\right)$. The landscape of the park is mainly flat, up to $132 \mathrm{~m}$ a.s.l., with several tunnel-valley lakes. The forests in WNP (61\% of total area) are dominated 
by Scots pine, Pinus sylvestris (73\% of forest area in 2001), which originates from the afforestation carried out at the turn of the nineteenth and twentieth centuries. The naturalization of tree stands was aimed at increasing the share of broad-leaved species, mainly pedunculate oak, Quercus robur, a strategy which has been continued since the 1960s (Bednorz 1997; Balcerkiewicz and Pawlak 2001). The study was carried out on four study plots: Wypalanki, Wiry, Jeziory, and Puszczykowo, which encompassed 1638 ha of the forest. Study plots predominantly consisted of pinedominated stands (except in the Puszczykowo plot). Some $40 \%$ of the study plots were covered by deciduous forests, mainly pedunculate oak, where $79 \%$ of trees were older than 80 years. Beech stands covered $2.5 \%$ of the forest area.

\section{Materials and methods}

Data were collected in 2013-2015. In each study plot, we located all cavities excavated by Black Woodpeckers. We conducted a survey of cavities from the late autumn through the winter preceding the breeding season. To determine the presence of Black Woodpeckers and secondary cavity users, we checked all cavities from the ground using a pole-mounted video camera. Our system included a highresolution mini camera (BU-18 550TV), receiver/transmitter set (TXRX-2455), portable digital video recorder (PV-500LITE), lighting system, boom, and telescopic pole. The receiver/transmitter set allows video and audio transmissions to be conducted wirelessly from a camera to a handheld video recorder, where images can be viewed and recorded. The camera images allowed us to determine the clutch and brood size. The maximum height of the inspected nests was $18 \mathrm{~m}$. Breeding cavities of Black Woodpeckers were checked 189 times (mean 5.7 times per cavity). In this way all the nesting attempts were checked every year. Most cavities $(n=24 ; 73 \%)$ were found during egg-laying. We checked cavities found with a full clutch around the anticipated hatching date and back-calculated the date of commencement of egg-laying. We assumed that the female laid one egg/day and that incubation lasted for 11 days (own unpublished data). The number of breeding pairs was estimated to range from nine to 11 , in consecutive years, and the mean density of Black Woodpeckers in study plots was 0.63 pair/100 ha of forest area (range $0.39-1.54$ pair/100 ha in study plots).

We grouped the cavity as "new" or "old" based on the freshness of excavation. Fresh cavities were made apparent by the presence of a newly chiseled entrance with a bright edge and a large amount of wood chips at the base of the tree. However, it is likely that new cavities were in fact initiated during the previous years as part of an long-term excavation strategy (Meyer and Meyer 2001; Zahner et al. 2012).
Excavation usually begins with a cavity start or trial cavity that may not be finished the same year. Old cavities were indicated by a dark edge around the entrance and the lack of, or a small amount of, wood chips at the base of the tree.

We used four parameters to describe trees with cavities excavated by Black Woodpeckers: tree species, tree viability (living tree, dying tree, and dead tree), diameter at breast height, and the height of the cavity entrance above the ground (cavity height). To estimate the floor area and volume of each cavity, we used camera images. Freeze frames extracted from video images were calibrated based on the mean egg length of Black Woodpeckers [34 mm (Cramp and Simmons 1985)]. Following this procedure, the two perpendicular diameters of the floor were measured to the nearest centimeter. Floor area was then calculated as an ellipse based on floor measurements. Estimations of cavity depth were based on the reference lengths (egg length) on the floor and their changes with different height planes of the cavity (this method was calibrated in the laboratory), and the distance from the bottom of the entrance hole to the floor of cavity. Cavity volume was estimated as cavity depth, multiplied by floor area. Since cavity dimensions change in time, we measured cavities for each breeding season. We used video images with a ruler placed at the end of the boom to measure the horizontal and vertical diameter of the cavity entrance.

Since most cavities were inhabited for more than 1 year, to exclude pseudoreplication in nest-site characteristics, we used each cavity tree only once in subsequent analyses, except to determine the internal dimension of cavities. We used relative laying dates to rule out the impacts of annual timing of breeding. We defined nest success in the traditional way, as the percentage of observed nests that were successful. We also estimated nest success based on the daily survival rate of nests using the Mayfield method (Mayfield 1975), with error terms calculated from Johnson (1979). To calculate the probability of nest survival, we assumed that the median length of the nesting period from the day of first egg-laying to the end of the nestling period was 44 days (own unpublished data).

We estimated the survival functions of offspring over time (from the day of egg-laying) in new and old cavities. The calculation was based on the Kaplan-Meier method and the difference between categories was tested with the log-rank $\chi^{2}$-statistic. To determine the potential effect of cavity age, volume, and floor area on the survival time of nesting period (Wiebe and Swift 2001), we used the Cox proportional hazards model (Kleinbaum 1996) in the Survival package (Therneau 2017). Since floor area and cavity volume were strongly correlated $(r=0.69)$, and may have affected the result of multiple regression analysis (Dormann et al. 2013), we constructed three models: a model including the cavity age (model 1), a model including the cavity 
age and cavity volume (model 2), and a model including the cavity age and floor area (model 3 ). To assess the global statistical significance of each model, we used a likelihoodratio (LR) test.

We used the generalized linear mixed effects model (GLMM) in the lme4 package (Bates et al. 2014), to test the effects of relative laying date, cavity age, and year as fixed effects on the number of fledglings. We did not test the effect of explanatory variables on clutch size due to its low variation. In GLMM, we treated cavity identity as a random effect to control for a lack of independence of nest sites in different years (some cavities were used in more than 1 year). Since the random effect was inert (LR test, $P>0.05$ ), it could be removed. In consequence, we ran linear models (LM) to test effects.

In the analysis of the effects of relative laying date, cavity age, and year on the number of fledglings, we used a set of eight candidate models: an intercept-only model (model 1 ), a model including the relative laying date (model 2), a model including the cavity age (model 3 ), a model including the year (model 4), a model including the relative laying date and cavity age (model 5), a model including the relative laying date and year (model 6), a model including the cavity age and year (model 7), and a model including all studied parameters (model 8). To perform a global validation of linear model assumptions, we used the gvlma package (Peña and Slate 2006). If the global test of the model's assumption was not satisfied $(P<0.05)$, we used Cook's distance to find influential outliers in a set of predictor variables in the model (Cook and Weisberg 1982). Influential points $(n=2)$ were removed from the analyses, after all the assumptions of each linear model were acceptable $(P>0.05)$. The relative support for each model was assessed using Akaike's information criterion corrected for small sample size (AICc). The subset of models with substantial support $(\Delta \mathrm{AICc}<2 \mathrm{com}-$ pared to the best model) was selected, with their parameter estimates and SEs averaged (Burnham and Anderson 2002) using the MuMIn package (Bartoń 2015). For all models,
Akaike weights were calculated to provide a measure of the probability that a given model was the most strongly supported in the model set, with higher weights indicating better explanatory power.

Since nest site characteristics were normally distributed (Shapiro-Wilk test, $P>0.05$ ) and had equal variances (Levene test, $P>0.05$ ), a $t$-test was used to compare the means between trees with old and new cavities, and between internal dimensions of the two types of cavity. In other analyses, nonparametric tests were used. All analyses were carried out using R version 3.3.2 (R Development Core Team 2016). Values reported are means \pm SD or medians \pm interquartile range (IQR). All the employed tests were two-tailed.

\section{Results}

\section{Nest site characteristics}

In WNP, Black Woodpeckers bred exclusively in European beeches. Cavities were excavated mainly in living trees (94.5\%; $n=21)$. Out of 33 breeding attempts, $27(81.8 \%)$ took place in old ( $\geq 1$ year) cavities. During the study period, two cavities were reused three times, seven were used twice, and 13 once. Among them there were 16 old and six new cavities. There were one, three, and two new excavations during the consecutive years of the study period. Breeding cavities were mainly located in close proximity to the unused cavities; four cavities (three old and one new) were at a distance of $>100 \mathrm{~m}$ from the nearest unused cavity. The mean diameter at breast height of cavity trees was $49.6 \pm 12.4 \mathrm{~cm}$ (range 36.0-69.0; $n=22$ ). The mean height of the nest entrance from the ground level was $12.4 \pm 3.2 \mathrm{~m}$ (range $5.9-18.3 ; n=22$ ). There were no significant differences in the diameter at breast height, height of the cavity entrance from the ground level, and the cavity dimensions between old and new cavities (Table 1).

Table 1 Nest site characteristics of Black Woodpeckers in relation to cavity age

\begin{tabular}{|c|c|c|c|c|c|c|c|c|}
\hline \multirow[t]{3}{*}{ Variable } & \multicolumn{6}{|l|}{ Cavity age } & \multirow[t]{3}{*}{$t$} & \multirow[t]{3}{*}{$P$} \\
\hline & \multicolumn{3}{|l|}{ Old } & \multicolumn{3}{|l|}{ New } & & \\
\hline & Mean \pm SD & Range & $n$ & Mean \pm SD & Range & $n$ & & \\
\hline Diameter at breast height $(\mathrm{cm})$ & $49.7 \pm 8.2$ & $36.0-69.0$ & 16 & $49.4 \pm 6.0$ & $42.5-56.5$ & 6 & 0.09 & 0.931 \\
\hline Cavity height (m) & $13.0 \pm 3.3$ & $5.9-18.2$ & 16 & $10.8 \pm 2.2$ & $8.4-14.4$ & 6 & 1.55 & 0.136 \\
\hline Vertical entrance diameter $(\mathrm{cm})$ & $11.1 \pm 2.2$ & $6.8-15.5$ & 16 & $12.9 \pm 1.6$ & $11.0-15.2$ & 6 & -1.88 & 0.074 \\
\hline Horizontal entrance diameter $(\mathrm{cm})$ & $7.5 \pm 0.7$ & $6.5-9.2$ & 16 & $8.2 \pm 0.8$ & $7.0-9.0$ & 6 & -1.89 & 0.073 \\
\hline Cavity depth $(\mathrm{cm})$ & $41.5 \pm 6.2$ & $27-37$ & 27 & $39.5 \pm 7.2$ & $31-50$ & 6 & 0.70 & 0.490 \\
\hline Floor area $\left(\mathrm{cm}^{2}\right)$ & $232.4 \pm 25.0$ & $180.1-283.6$ & 27 & $211.4 \pm 40.9$ & $185.3-290.3$ & 6 & 1.65 & 0.109 \\
\hline Cavity volume $\left(\mathrm{dm}^{3}\right)$ & $9.67 \pm 1.88$ & $5.94-13.56$ & 27 & $8.29 \pm 1.86$ & $6.60-11.32$ & 6 & 1.63 & 0.113 \\
\hline
\end{tabular}




\section{Timing of breeding}

The earliest first-egg date in following years was 22 April 2013, 3 April 2014, and 1 April 2015. The latest commencement of egg-laying was 26 April, 6 May, and 13 May, respectively. Median laying dates in consecutive years were 22 April (IQR 22-24 April; $n=11$ ), 7 April (IQR 3/4-9/10 April; $n=12$ ), 11/12 April (IQR 6-13 April; $n=10$ ), and they differed significantly between years (Kruskal-Wallis test $H_{2,33}=17.91 ; P=0.0001$ ). In 2013, the breeding started markedly later, compared to other years (multiple comparisons of mean ranks for groups: 2013 vs. $2014-P<0.001$; 2013 vs. $2015-P<0.01 ; 2014$ vs. $2015-P=1.0$ ), as a result of the cold spring. The median of relative laying date in old cavities was 5.5 days earlier than in new cavities (Mann-Whitney $U$-test, $Z=-2.23 ; P=0.026 ; n_{1}=25$ and $n_{2}=6$, respectively; replacement breeding attempts were excluded from the analysis) (Fig. 1).

\section{Reproductive success}

Mean clutch size was $4.0 \pm 0.5$ eggs (range $2-5 ; n=33$ ), with $88 \%$ of the nests $(n=29)$ containing four eggs. Other clutches contained two, three, and five $(2 \times)$ eggs, respectively. In the first breeding attempt, the clutch size was $4.0 \pm 0.5$ eggs $(n=25)$ in old cavities and $3.8 \pm 0.4(n=6)$ in new cavities; however, the sample size was too small and clutch size too invariable to test for the differences.

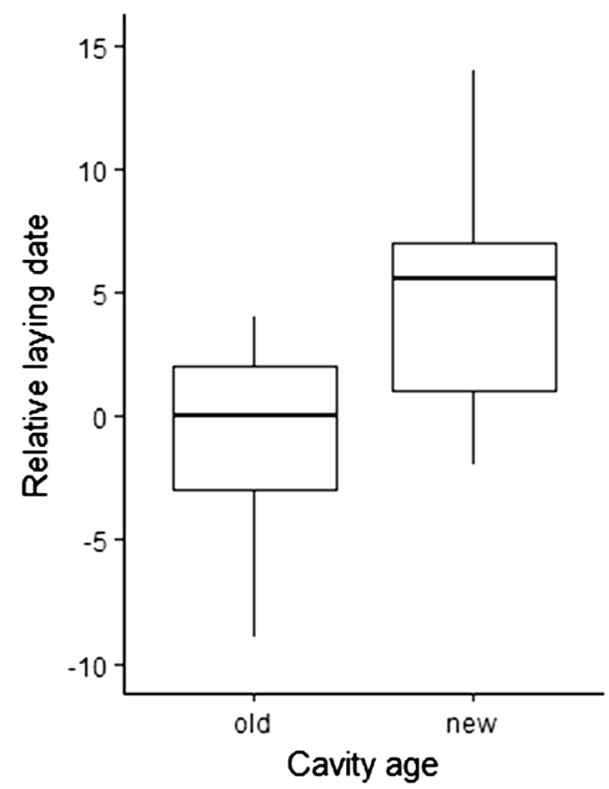

Fig. 1 Relative laying dates of first eggs of Black Woodpeckers against cavity age. Median, interquartile range (IQR) (hinges), and range (whiskers) are given. Sample sizes are 25 breeding attempts in old cavities and six breeding attempts in new cavities
Of 131 eggs laid by Black Woodpeckers, 102 hatched (77.9\%; $n=33)$. Excluding the brood that failed completely before hatching, the proportion of eggs that hatched reached $80.3 \%$ (127 eggs laid versus 102 hatched; $n=32$ ). Hatching success varied from 0.82 in old cavities to 0.68 in new cavities but did not differ significantly (Mann-Whitney $U$-test; $Z=1.51 ; P=0.111 ; n_{1}=27$ and $n_{2}=5$, respectively). Hatching success was not correlated with clutch size $(r=0.2 ; P=0.273 ; n=32)$. The mean number of fledglings from all nests was $2.9 \pm 1.1 \mathrm{eggs}$ $(n=33)$. However, the mean number of fledglings from broods that did not fail completely was $3.1 \pm 0.8(n=31)$. In first successful breeding attempts, the number of fledglings in old cavities was larger $(3.2 \pm 0.8 \mathrm{eggs} ; n=24)$ than in new cavities $(2.4 \pm 0.5 ; n=5)$, and the medians of the two samples differed significantly (Mann-Whitney $U$-test, $Z=2.27 ; P=0.023$ ).

The percentage of nests that fledged at least one chick was $93.9(n=33)$. Daily survival rate was 0.9986 ( $\mathrm{SE}=0.0010 ; 95 \%$ CI $0.9966-1.0000 ; 1436$ nest-days without losses, 2 nest-days with losses), and nest success was $94.1 \%$ (95\% CI 86.2-100.0) for 44 days. Of 33 breeding attempts, two were destroyed by unidentified predators-one brood was lost in a new cavity near the hatching period and the other in an old cavity during the nestling period. Partial losses were found in five cavities. A dead nestling was recorded in one cavity; in three nests, one nestling disappeared; in the other two nestlings disappeared; all except one of these losses were recorded in old cavities.

The proportion of nestlings surviving to the end of the nestling period was 0.812 in old cavities $(\mathrm{SE}=0.040$; 95\% CI $0.738-0.894)$ and $0.632(\mathrm{SE}=0.111 ; 95 \% \mathrm{CI}$ $0.448-0.890)$ in new cavities; these proportions did not differ significantly (log-rank $\chi^{2}=-1.59, P=0.112$; replacement breeding attempts and those that failed completely were excluded from the analysis). Survivorship stayed at the level 1 until the hatching period (days 14-18), then it dropped rapidly, especially in new cavities (Fig. 2). The Cox proportional hazards models showed that age, cavity floor area, and volume did not affect the risk of death significantly. The hazard ratio (HR) in each model indicated that offspring in new cavities had a higher risk of death than offspring in old cavities, i.e., growing up in a new cavity increased the hazard by a factor of 2 . However, because the confidence intervals (CI) for HR include 1, these results fail to be significant (Table 2).

Only three models (models 5, 3 and 2) out of eight examining the effect of relative laying date, cavity age, and year on the number of fledglings were well supported by the data, as indicated by the $\triangle \mathrm{AICc}$ value (Table 3 ). The parameters based on model averaging suggest that the number of 


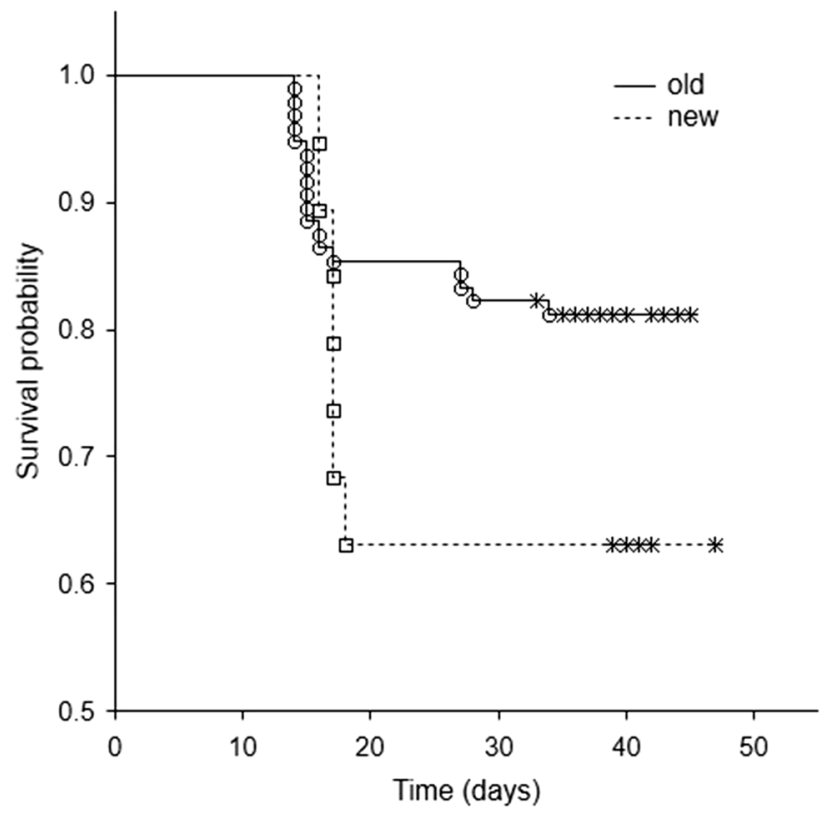

Fig. 2 Kaplan-Meier survival functions of Black Woodpecker offspring in old ( $n=96$ offspring and 18 events) and new cavities $(n=19$ offspring and 7 events). Circles and squares Complete data, asterisks censored data

fledglings was larger in old cavities than in new cavities as the CI did not include zero (Table 4; Fig. 3).

\section{Discussion}

Age of parent Black Woodpeckers and duration of the pair-bond may be important determinants of reproduction parameters, especially if yearlings and new pairs tend to use new cavities. Pairs that have bred together for several years might have improved skills, such as coordination of incubation duties and foraging abilities, which might positively affect their reproductive performance. In Lesser Spotted Woodpeckers, Dryobates minor, old pairs start egg-laying earlier and raise more young than new pairs (Wiktander et al. 2001). In Red-cockaded Woodpeckers, Picoides borealis, older females were found to lay eggs earlier and were more productive than inexperienced females, experienced females who change mates, and inbred birds (Schiegg et al. 2002). We did not find significant differences between pair-bond duration (pairs of birds that bred together in a previous year vs. pairs of birds that bred together for the first time) in Black Woodpeckers and the number of new excavations $\left(\chi^{2}\right.$-test with Yates correction; $P>0.05$ ) in data reported by Hansen (1989) and Christensen (2006). The high frequency of new excavations reported by Hansen (1989) was most likely affected by the high rates of old cavities being lost, for example usurped by Jackdaws Corvus monedula. Our analysis revealed no differences between nesting success (proportion of breeding attempts that were successful) in Black Woodpeckers in reused compared to freshly excavated cavities in data reported by Christensen (2006) $\left(\chi^{2}-\right.$ test with Yates correction; $P>0.05$; replacement breeding attempts were excluded from the analysis); however, this author showed that when only new excavations were analyzed, pairs having bred together for the first time had significantly lower nesting success than that of pairs having bred together at least once. These data suggest that in Black Woodpeckers pair-bond duration may have additional independent effects on reproductive parameters in old and new cavities. Finally, Wiebe (2017) found that age, breeding experience, and mate retention had little influence on excavation rates in Northern Flickers Colaptes auratus.

In this study, our data show that during the time window for reproduction, egg-laying starts significantly earlier in old

Table 2 Model coefficients of the variables included in the Cox proportional hazards models explaining the effects of cavity age, floor area and cavity volume on survival probability of offspring

\begin{tabular}{|c|c|c|c|c|c|c|c|}
\hline Model & Variable & Estimate & SE & Wald statistic & $P$ & $\begin{array}{l}\text { Hazard ratio } \\
\text { (HR) }\end{array}$ & $95 \% \mathrm{CI}$ of the HR \\
\hline 1 & $\begin{array}{l}\text { Cavity age } \\
\text { LR test }=2.19, d f=1, P=0.139\end{array}$ & 0.699 & 0.446 & 1.567 & 0.117 & 2.012 & $0.839-4.825$ \\
\hline 2 & $\begin{array}{l}\text { Cavity age } \\
\text { Floor area } \\
\text { LR test }=2.38, d f=2, P=0.305\end{array}$ & $\begin{array}{l}0.727 \\
0.003\end{array}$ & $\begin{array}{l}0.449 \\
0.007\end{array}$ & $\begin{array}{l}1.618 \\
0.434\end{array}$ & $\begin{array}{l}0.106 \\
0.664\end{array}$ & $\begin{array}{l}2.068 \\
1.003\end{array}$ & $\begin{array}{l}0.858-4.988 \\
0.990-1.016\end{array}$ \\
\hline 3 & $\begin{array}{l}\text { Cavity age } \\
\text { Cavity volume } \\
\text { LR test }=2.20, d f=2, P=0.334\end{array}$ & $\begin{array}{l}0.702 \\
0.005\end{array}$ & $\begin{array}{l}0.450 \\
0.106\end{array}$ & $\begin{array}{l}1.560 \\
0.048\end{array}$ & $\begin{array}{l}0.119 \\
0.962\end{array}$ & $\begin{array}{l}2.018 \\
1.005\end{array}$ & $\begin{array}{l}0.835-4.877 \\
0.817-1.237\end{array}$ \\
\hline
\end{tabular}

Initial number of offspring in old cavities $n=96$ and 18 events, number of offspring in new cavities $n=19$ and 7 events

$C I$ Confidence interval, $L R$ likelihood ratio 
Table 3 Model-selection statistics for the analysis of the effects of relative laying date, hole age and year on number of fledglings

\begin{tabular}{llllll}
\hline Model & Model function & $d f$ & $\mathrm{AICc}^{\mathrm{a}}$ & $\Delta \mathrm{AICc}^{\mathrm{b}}$ & Weight $^{\mathrm{c}}$ \\
\hline 5 & Relative laying date + cavity age & 4 & 57.7 & 0.00 & 0.357 \\
3 & Cavity age & 3 & 57.8 & 0.11 & 0.337 \\
2 & Relative laying date & 3 & 59.0 & 1.30 & 0.186 \\
6 & Relative laying date + year & 5 & 62.3 & 4.55 & 0.037 \\
7 & Cavity age + year & 5 & 62.7 & 4.98 & 0.030 \\
8 & Relative laying date + cavity age + year & 6 & 62.8 & 5.05 & 0.029 \\
1 & Intercept-only model & 2 & 63.4 & 5.65 & 0.021 \\
4 & Year & 4 & 66.6 & 8.93 & 0.004 \\
\hline
\end{tabular}

Sample sizes are 23 breeding attempts in old cavities and five breeding attempts in new cavities

aAkaike's information criterion

${ }^{\mathrm{b}}$ Difference in AICc relative to the model with the lowest AICc

${ }^{\mathrm{c}}$ Models are ranked according to their Akaike weight; higher weights indicate more parsimonious models
Table 4 Model coefficients of the variables included in the bestranked models explaining the effects of cavity age and relative laying date on the number of fledglings

\begin{tabular}{lcccc}
\hline Variable & Estimate & SE & $2.5 \%$ CL & $97.5 \%$ CL \\
\hline Relative laying date & -0.059 & 0.033 & -0.126 & 0.007 \\
Cavity age (new) & -0.777 & 0.344 & -1.481 & -0.074 \\
\hline
\end{tabular}

Estimation based on model-averaging. See Table 3 for the full list of models tested and sample sizes

CL Confidence limit

cavities than in new cavities. Similar results were obtained in Thuringia (Germany), where the onset of egg-laying in old cavities occurred 8 days earlier than in newly excavated cavities (Lange 1996). Since, in WNP, Black Woodpeckers preferentially (82\%) used old cavities rather than building new ones, it is likely that this behavior is adaptive for this species as it offers time and energy savings. Although the Black Woodpecker is a strong excavator, the excavation process in living beeches may require up to several years to finish a cavity (Glutz von Blotzheim and Bauer 1980; Lang and Rost 1990a; Lange 1996; Zahner et al. 2012). The benefits of nest reuse, such as earlier laying and a higher chance of immediately initiating another breeding attempt if the previous one has not succeeded, most likely outweigh the potential costs associated with nesting in old cavities, such as increased ectoparasitism and rates of predation (Short 1979; Nilsson et al. 1991; Hauber 2002; Wiebe et al. 2007). However, Wiebe (2009) found relatively small effects of ectoparasites in reused cavities of Northern Flickers. Lange and Rost (1990a) found pronounced fidelity for years to particular beech trees with old cavities for breeding and roosting purposes. In another study, Lange (1996) found that $75 \%$ of the breeding attempts of Black Woodpeckers in beeches, the
Fig. 3 Number of Black Woodpecker fledglings against relative laying date (a) and cavity age (b). a Regression line (solid) and $95 \%$ confidence limit (grey area); b median, interquartile range (IQR) (hinges), and range (whiskers) are given. Sample sizes are 23 breeding attempts in old cavities and five breeding attempts in new cavities
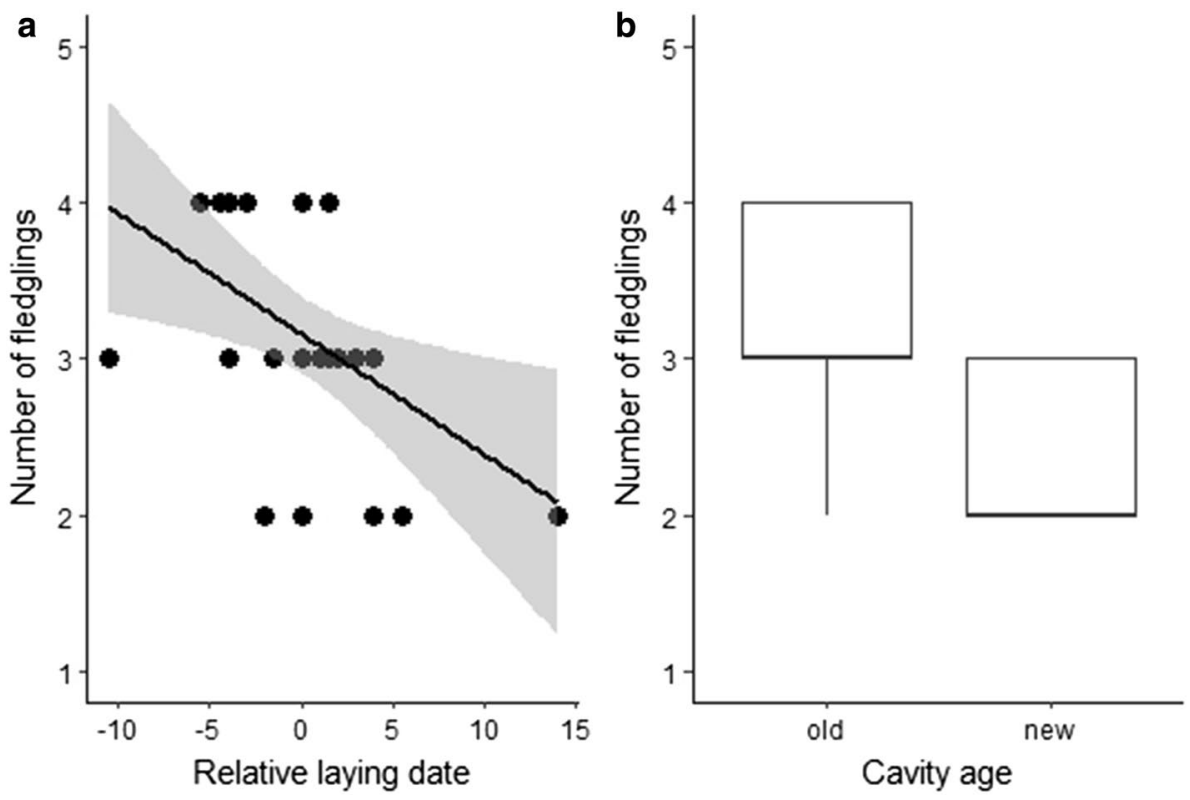
most frequently used tree by species in Thuringia (68\%), occurred in old nests. These data suggest a low effect of parasites on the cost of nest reuse in Black Woodpeckers.

Most of the broods in WNP were in old cavities; nesting success was high (0.94) and exceeded the average nesting success of 12 studies in Europe (0.79; range 0.55-0.96) (Paclik et al. 2009). Pine Marten Martes martes is considered to be one of the most potential predators of large cavity users (Nilsson et al. 1991; Rolstad et al. 2000; Zahner et al. 2017). Though we observed dens of Pine Martens in cavities excavated in beeches in close proximity to cavities of Black Woodpeckers ( $57 \pm 30 \mathrm{~m}$; range $23-87 \mathrm{~m} ; n=5)$, their influence on broods was probably small. Black Woodpeckers have effective strategies to defend their nests, e.g., guarding the nest during different periods of the nesting cycle (Paclik et al. 2009; Zahner et al. 2017). These factors suggest that the presumed risk of nest predation in Black Woodpeckers is not associated with old cavities.

Earlier studies have found that the excavation of a new cavity is most frequently motivated by the presence of water in old cavities, cavity usurpation by other species or due to the failure of breeding during the early stages of reproduction (Hansen 1989; Nilsson et al. 1991; Meyer and Meyer 2001; Christensen 2006). Moreover, Lang and Rost (1990a) found that some of new cavities were never used for breeding shortly after their completion. However, studies conducted in the northern range of hemiboreal forests in Europe (Uppland, Sweden) indicate a lower frequency of breeding in old cavities than that of populations in Central Europe (Lang and Rost 1990a; Nilsson et al. 1991; Lange 1996; Christensen 2006). Nilsson et al. (1991) suggested that Black Woodpeckers usually excavate a new breeding cavity each year to avoid predation. According to their results, breeding success in newly excavated cavities was larger (71\%) than in old cavities (38\%). High rates of predation in Black Woodpecker cavities in Uppland were probably partly associated with the distinctly lower height of nests above the ground (mean $7.2 \mathrm{~m}$ ) than nests in Central Europe [e.g., $12.4 \mathrm{~m}$ in WNP (see also Kosiński et al. 2011)]. Results of a nest predation experiment in Sweden showed a low risk of predation for nests at $>9 \mathrm{~m}$ above ground level (Johnsson 1993). However, Rolstad et al. (2000) reported that in the middle boreal zone in Scandinavia, Black Woodpeckers tend to strongly select dead trees and old cavities and reject Scots pine, despite there being no difference in nest predation rate.

It appears that excavation is an attractive alternative for Black Woodpeckers when nesting in an old cavity is riskier and the hardness of the wood of preferred trees is relatively low. Lower wood hardness of aspen (Janka hardness scale $1.650 \mathrm{~N}$ ), the principal deciduous tree species providing nesting habitat for Black Woodpeckers in boreal and boreonemoral forests in Sweden (Nilsson et al. 1991; Rolstad et al. 2000), may reduce time and energy costs of excavation of new cavities each year. The cost of excavation in beeches, the most frequently used tree species in Central and Western Europe, is much higher than in aspens as the wood is harder (6.460 N; http://www.wood-database.com/). Thus, it can be argued that the causes and consequences of cavity reuse vary according to local conditions as a result of different risks of predation, life span of cavities, and the cost of excavation in different tree species (Rolstad et al. 2000; Wiebe et al. 2007).

In this study, we did not observe a seasonal decline in clutch size. This observation might be due to the low variation in clutch size and the low number of replacement clutches. Similar to earlier studies, we did not find any significant differences between the size of clutches in old and new cavities. Wiebe et al. (2007) found declining clutch sizes in new cavities in comparison to old cavities in nine out of 14 woodpecker populations; however, this was statistically significant only within one species, the Red-naped Sapsucker Sphyrapicus nuchalis. Moreover, clutches of Northern Flickers were also found to be slightly smaller in new excavations than in reused cavities (Wiebe 2014). These results suggest that clutch size is not affected by the energy cost of cavity excavation. Although a number of studies have focused on reproductive success in Black Woodpeckers, studies on variation in clutch size are scarce. To our knowledge, only one study has explored the effect of age of cavity on the number of eggs. Nilsson et al. (1991) found that in Central Sweden, clutch size does not differ between old and new cavities. Studies based on experimentally manipulated nest-building effort in small passerine species show that increasing the costs of nest building in Eastern Phoebes Sayornis phoebe, European Pied Flycatchers Ficedula hypoleuca, and Blue Tit Cyanistes caeruleus has no significant effect on the clutch size (Hauber 2002; Moreno et al. 2008; Mainwaring and Hartley 2016).

Although the difference in survival probability was not found to be statistically significant between old and new cavities (most likely as a result of a low number of offspring in new cavities), we found that survivorship dropped rapidly around the hatching period, especially in new cavities. The lower hatchability in new cavities than in old cavities suggests that Black Woodpeckers are more constrained with respect to attending to incubation as their energy reserves are reduced at least by the costs of excavation; however, other factors, for example, acquiring insufficient food for the hatchlings in new cavities due to the result of newly formed or inexperienced pairs, may lead to lower survivorship of the hatchlings. Moreno et al. (2010) found that Pied Flycatchers spend a higher proportion of time incubating their eggs when the cost of nest building is lower. These data suggest that nest construction is an energetically expensive activity and has important consequences for the physiological performance of birds. 
In Black Woodpecker, the number of fledglings can be best explained by the model with the age of the cavity and the relative laying date. However, our model parameters show that the number of fledglings can be determined primarily by the age of the cavity, which was found to be larger in old than in new cavities. These data confirm earlier suggestions that the costs of nest building are carried over to the subsequent stages of reproduction (Mainwaring and Hartley 2013). For example, in Pied Flycatchers, Moreno et al. (2010) found that energy savings for adults during nest construction are shunted directly to chicks and expressed in higher provisioning at early nestling stages and in improving nestling growth. Nevertheless, our results should be interpreted with caution because we did not directly measure the energy cost required to excavate a cavity; the sample size of new excavations was relatively low compared to other studies, and the proportion of new and old pair-bonds and their consequences for reproduction in both old and new cavities is unknown. Some studies reporting the effect of cavity age on the number of fledglings in Black Woodpeckers did not find any significant differences between old and new cavities. However, in two studies in German beech forests and one study on the German-Denmark border, Black Woodpeckers tended to produce large number of fledglings in old cavities (Lang and Rost 1990b; Lange 1996; Christensen 2006), whereas in Sweden, there was a reverse tendency (Nilsson et al. 1991).

The difference in the number of fledglings attaining independence in old and new cavities may also be affected by their different dimensions. Wiebe and Swift (2001) found that crowding, which may be a byproduct of smaller inner dimensions of new cavities, slightly decreased nestling survival in Northern Flickers. We did not find any statistically significant difference between the floor area in new and old cavities in Black Woodpeckers; however, floor area was found to be around $10 \%$ smaller in new cavities than in reused cavities, which was close to the reported value for Northern Flickers [14\% (Wiebe and Swift 2001)]. Moreover, we found that the area of the floor and volume of the cavity does not affect the risk of death. Since survivorship remained at the same level throughout the fledging period in old and new cavities, we can conclude that there are no fitness consequences to the relationship between the number of nestlings and the cavity size. In Northern Flickers, clutch size is considerably larger (about eight eggs) and more variable (from four to 11) than in Black Woodpeckers (Wiebe and Swift 2001; Wiebe et al. 2007). Therefore, more problems are expected due to crowding in woodpecker species with larger clutches and broods. Black Woodpeckers may not always excavate large spaces in new cavities because nest building is an energetically expensive and time-consuming activity. It is likely that the large dimensions of reused cavities in subsequent years are due to their enlargement, renovation, or wood decay.

\section{Conclusion}

Our data are consistent with the hypothesis that cavity excavation is energetically expensive for Black Woodpeckers nesting in living beech trees, and support predictions of tradeoffs between nest building and different components of reproduction. We found that reusing cavities offers the advantages of earlier laying, higher hatchability of eggs, and an increased number of fledglings. Contrary to previous studies, we did not find a difference in clutch size between old and new cavities due to its low variation in the population. This is probably the first report demonstrating that energetic costs of nest building in woodpeckers may be carried over into subsequent stages of their reproduction. Although other explanations for the observed effects are possible, including pair-bond duration and experience of the parents, which may affect the dichotomy of reproductive parameters in old and new cavities, previous studies provide little evidence for this in Black Woodpeckers. Our study shows that nest reuse may be adaptive for Black Woodpeckers as it offers time and energy savings needed for cavity excavation, and increases productivity compared to those pairs that are forced into excavating a new cavity. Responsible forest management should consider the necessity to protect beech trees with old cavities, which are frequently used by Black Woodpeckers and some secondary cavity users.

Acknowledgements The study was performed under a license of the Directorate of Wielkopolska National Park. We thank Grzegorz Neubauer for suggestions that improved the statistical modeling. The manuscript was improved by the helpful comments of three reviewers.

Open Access This article is distributed under the terms of the Creative Commons Attribution 4.0 International License (http://creativeco mmons.org/licenses/by/4.0/), which permits unrestricted use, distribution, and reproduction in any medium, provided you give appropriate credit to the original author(s) and the source, provide a link to the Creative Commons license, and indicate if changes were made.

\section{References}

Balcerkiewicz S, Pawlak G (2001) Szata roślinna Wielkopolskiego Parku Narodowego. W: Wojterska M (ed) Szata roślinna Wielkopolski i Pojezierza Południowopomorskiego. Przewodnik sesji terenowych 52. Zjazdu Polskiego Towarzystwa Botanicznego, 24-28 Września 2001, Poznań (In Polish)

Bartoń K (2015) Package 'MuMIn': multi-model inference. R package, version 1.15 .6 
Bates D, Maechler M, Bolker B, Walker S (2014) lme4: linear mixedeffects models using Eigen and S4. R package version 1.1-7

Bednorz J (1997) Birds of the Wielkopolska National Park. Prace Zakł Biol i Ekol Ptaków UAM 8:1-68 (In Polish with English summary)

Burnham KP, Anderson DR (2002) Model selection and multimodel inference: a practical information-theoretic approach, 2nd edn. Springer, New York

Christensen H (2004) Nutzung von Schwarzspecht-Höhlen im deutschdänischen Grenzbereich durch den Schwarzspecht (Dryocopus martius) selbst und andere Tierarten. Corax 19:417-423

Christensen H (2006) Warum bauen Schwarzspechte (Dryocopus martius) neue Bruthöhlen? Ergebnisse aus dem deutsch-dänischen Grenzbereich. Corax 20:120-128

Cook RD, Weisberg S (1982) Residuals and influence in regression. Chapman and Hall, New York

Cramp S, Simmons KEL (eds) (1985) Handbook of the birds of Europe, the Middle East and North Africa. The Birds of the Western Palearctic: Terns to Woodpeckers, vol IV. Oxford University Press, Oxford

Development Core Team R (2016) R: a language and environment for statistical computing. R Foundation for Statistical Computing, Vienna

Dormann CF, Elith J, Bacher S, Buchmann C, Carl G, Carré G, Marquéz JRG, Gruber B, Lafourcade B, Leitão PJ, Münkemüller T, McClean C, Osborne PE, Reineking B, Schröder B, Skidmore AK, Zurell D, Lautenbach S (2013) Collinearity: a review of methods to deal with it and a simulation study evaluating their performance. Ecography 36:27-46

Glutz von Blotzheim UN, Bauer K (1980) Handbuch der Vögel Mitteleuropas, vol 9. Columbiformes-Piciformes. Aula, Wiesbaden

Hansen F (1989) Sortspættens Dryocopus martius udmejsling og genbrug af redehuller på Bornholm. Dansk Orn Foren Tidsskr $83: 125-129$

Hauber ME (2002) Is reduced clutch size a cost of parental care in Eastern Phoebes (Sayornis phoebe)? Behav Ecol Sociobiol 51:503-509

Johnson DH (1979) Estimating nest success: the Mayfield method and an alternative. Auk 96:651-661

Johnsson K (1993) Nest site quality in old Black Woodpecker holes-a predation experiment. In: Johnsson K (ed) The Black Woodpecker Dryocopus martius as a keystone species in forest. $\mathrm{PhD}$ thesis. Report 24. Department of Wildlife Ecology, Swedish University of Agricultural Sciences, Uppsala, Sweden, pp 49-65

Johnsson K, Nilsson SG, Tjernberg M (1993) Characteristics and utilization of old Black Woodpecker Dryocopus martius holes by hole-nesting species. Ibis 135:410-416

Kleinbaum DG (1996) Survival analysis: a self-learning text. Springer, New York

Kosiński Z, Bilińska E, Dereziński J, Jeleń J, Kempa M (2010) The Black Woodpecker Drycocopus martius and the beech Fagus sylvatica as keystone species for the Stock Dove Columba oenas in western Poland. Ornis Pol 51:1-13 (In Polish with English summary)

Kosiński Z, Bilińska E, Dereziński J, Kempa M (2011) Nest-sites used by Stock Doves Columba oenas: what determines their occupancy? Acta Ornithol 46:155-163

Lang E, Rost R (1990a) Höhlenökologie und Schutz des Schwarzspechtes (Dryocopus martius). Vogelwarte 35:177-185

Lang E, Rost R (1990b) Brutaktivität, Bruterfolg und Schutz des Schwarzspechtes Dryocopus martius. Vogelwelt 111:28-39

Lange U (1993) Die Hohltaube (Columba oenas) im Landkreis Ilmenau (Thüringen). Anz Ver Thüring Ornithol 2:9-24

Lange U (1996) Brutphänologie, Bruterfolg und Geschlechterverhältnis der Nestling beim Schwarzspecht Dryocopus martius im IlmKreis (Thüringen). Vogelwelt 117:47-56
Mainwaring MC, Hartley IR (2013) The energetic costs of nest building in birds. Avian Biol Res 6:12-17

Mainwaring MC, Hartley IR (2016) Experimentally reduced nestbuilding costs result in higher provisioning rates but not increased offspring fitness in blue tits. Avian Biol Res 9:52-57

Mayfield HF (1975) Suggestions for calculating nest success. Wilson Bull 87:456-466

Meyer W, Meyer B (2001) Bau und Nutzung von Schwarzspechthöhlen in Thuringen. Abh Ber Museum Heineanum 5:121-131

Moreno J, Martinez J, Corral C, Lobato E, Merino S, Morales J, Martinez-de la Puente J, Tomás G (2008) Nest construction rate and stress in female Pied Flycatchers Ficedula hypoleuca. Acta Ornithol 43:57-64

Moreno J, Lobato E, González-Braojos S, Ruiz-de Castañeda R (2010) Nest construction costs affect nestling growth: a field experiment in a cavity-nesting passerine. Acta Ornithol 45:139-145

Newton I (ed) (1989) Lifetime reproduction in birds. Blackwell, Oxford

Nilsson SG, Johnsson K, Tjernberg M (1991) Is avoidance by Black Woodpeckers of old nest holes due to predators? Anim Behav 41:439-441

Paclik M, Misík J, Weidinger K (2009) Nest predation and nest defence in European and North American woodpeckers: a review. Ann Zool Fenn 46:361-379

Pakkala T, Tiainen J, Kouki J (2017) The importance of nesting cavity and tree reuse in the Three-toed Woodpecker Picoides tridactylus in dynamic forest landscapes. Ann Zool Fenn 54:175-191

Pasinelli G (2006) Population biology of European woodpecker species: a review. Ann Zool Fenn 43:96-111

Peña EA, Slate EH (2006) Global validation of linear model assumptions. J Am Stat Assoc 101:341-354

Perrins CM (1970) The timing of birds' breeding seasons. Ibis 112:242-255

Reid JM, Monaghan P, Ruxton GD (2000) Resource allocation between reproductive phases: the importance of thermal conditions in determining the cost of incubation. Proc R Soc Lond B 267:37-41

Rolstad J, Rolstad E, Sæteren Ø (2000) Black Woodpecker nest sites: characteristics, selection, and reproductive success. J Wildl Manage 64:1053-1066

Schiegg K, Pasinelli G, Walters JR, Daniels SJ (2002) Inbreeding and experience affect response to climate change by endangered woodpeckers. Proc R Soc Lond B 269:1153-1159

Short LL (1979) Burdens of the picid hole-excavating habit. Wilson Bull 91:16-28

Stearns SC (1992) The evolution of life histories. Oxford University Press

Therneau TM (2017) Package 'Survival'. Version 2.41-3

van Manen W (2012) Broedbiologie van de Zwarte Specht in Nederland. Limosa 85:161-170

Wiebe KL (2009) Nest excavation does not reduce harmful effects of ectoparasitism: an experiment with a woodpecker, the Northern Flicker Colaptes auratus. J Avian Biol 40:166-172

Wiebe KL (2014) Responses of cavity-nesting birds to fire: testing a general model with data from the Northern Flicker. Ecology 95:2537-2547

Wiebe KL (2017) Northern flickers only work when they have to: how individual traits, population size and landscape disturbances affect excavation rates of an ecosystem engineer. J Avian Biol 48:431-438

Wiebe KL, Swift TL (2001) Clutch size relative to tree cavity size in Northern Flickers. J Avian Biol 32:167-173

Wiebe KL, Koenig WD, Martin K (2007) Costs and benefits of nest reuse versus excavation in cavity-nesting birds. Ann Zool Fenn 44:209-217

Wiktander U, Olsson O, Nilsson SG (2001) Age and reproduction in Lesser Spotted Woodpeckers (Dendrocopos minor). Auk 118:624-635 
Winkler H, Christie DA (2002) Family Picidae (Woodpeckers). In: del Hoyo J, Elliott A, Sargatal J (eds) Handbook of the birds of the world, vol 7. Jacamaras to woodpeckers. Lynx, pp 296-555

Zahner V, Sikora L, Pasinelli G (2012) Heart rot as a key factor for cavity tree selection in the Black Woodpecker. For Ecol Manage 271:98-103

\section{Affiliations}

\section{Ziemowit Kosiński $^{1}$ [D $\cdot$ Łukasz Walczak $^{1}$}

$\triangle$ Ziemowit Kosiński

zkosinsk@amu.edu.pl

Łukasz Walczak

walczakl@amu.edu.pl
Zahner V, Bauer R, Kaphegyi TAM (2017) Are Black Woodpecker (Dryocopus martius) tree cavities in temperate beech (Fagus sylvatica) forests an answer to depredation risk? J Ornithol 158:1073-1079
Department of Avian Biology and Ecology, Institute of Environmental Biology, Faculty of Biology, Adam Mickiewicz University, Poznań, Umultowska 89, 61-614 Poznań, Poland 